\title{
SINTESIS STEARAMIDA DARI ASAM STEARAT DAN UREA MENGGUNAKAN PELARUT CAMPURAN : PENGARUH TEMPERATUR DAN WAKTU REAKSI
}

\section{SYNTHESIS OF STEARAMIDE FROM STEARIC ACID AND UREA USING MIXED SOLVENT: THE EFFECT OF TEMPERATURE AND REACTION TIME}

\author{
Muhammad Syukri* dan Zuhrina Masyithah \\ Departemen Teknik Kimia, Fakultas Teknik, Universitas Sumatera Utara \\ Jl. Almamater Kampus USU Medan 20155, Indonesia \\ *Email : anti_hacker87@yahoo.co.id
}

\begin{abstract}
Abstrak
Surfaktan merupakan suatu molekul yang memiliki gugus hidrofilik dan gugus lipofilik sehingga dapat mempersatukan campuran yang terdiri dari air dan minyak. Stearamida merupakan salah satu jenis surfaktan non-ionik. yang banyak dimanfaatkan dalam berbagai bidang. Tujuan penelitian ini untuk mengetahui waktu dan suhu optimum sintesis stearamida dari asam stearat dan urea dengan katalis zirkonium (IV) klorida dalam pelarut campuran. Pada penelitian ini, akan diamati pengaruh temperatur dan waktu reaksi terhadap sintesis surfaktan stearamida yang di sintesis dari asam stearat dan urea dengan katalis zirkonium (IV) klorida dalam pelarut campuran. Penelitian ini dilakukan pada temperatur $45^{\circ} \mathrm{C}, 55^{\circ} \mathrm{C}, 65^{\circ} \mathrm{C}, 75^{\circ} \mathrm{C}, 85^{\circ} \mathrm{C}$ dan $95^{\circ} \mathrm{C}$, waktu reaksi selama 1 jam, 2 jam, 3 jam, 4 jam, 5 jam, 6 jam , 7 jam dan 8 jam, rasio mol substrat 1:6 (b/b), pada rasio pelarut 2:1 (v/v), berat katalis 3\% (\%b), dan kecepatan pengadukan $250 \mathrm{rpm}$. Berdasarkan penelitian ini didapatkan kondisi yang optimal pada suhu $85^{\circ} \mathrm{C}$ dan waktu reaksi 3 jam.
\end{abstract}

Kata kunci: stearamida, asam stearat, surfaktan, suhu, waktu.

\begin{abstract}
Surfactant is a molecule which has hydrophilic group and a lipophilic group which can unify a mixture consisting of water and oil. Stearamide is one kind of surfactant non-ionic which has used on any aplication. This study aims to know about optimum of temperature and time on synthesis of stearamide from stearic acid and urea with zirconium (IV) chloride in mixed solvent. This study will be observed the effect of temperature and reaction time on the synthesis of stearamide surfactant from stearic acid and urea with zirconium (IV) chloride as catalyst in mixed solvent. This research was conducted at temperature of $45^{\circ} \mathrm{C}, 55^{\circ} \mathrm{C}, 65^{\circ} \mathrm{C}, 75^{\circ} \mathrm{C}, 85^{\circ} \mathrm{C}$ and $95^{\circ} \mathrm{C}$, reaction time of $1 \mathrm{hr}, 2$ $\mathrm{hr}, 3 \mathrm{hr}, 4 \mathrm{hr}, 5 \mathrm{hr}, 6 \mathrm{hr}, 7 \mathrm{hr}$ and $8 \mathrm{hr}$, substrate molar ratio at 1:6 (w/w), solvent ratio at 2:1 (v/v), weight of catalyst $3 \%(\% \mathrm{w})$, and stirring speed at $250 \mathrm{rpm}$. Based on this research, the optimum condition to synthesis stearamide surfactant was obtained at $85^{\circ} \mathrm{C}$ and reaction time at 3 hours.
\end{abstract}

Keywords: stearamide, stearic acid, surfactant, temperature, time.

\section{Pendahuluan}

Surfaktan memiliki gugus hidrofilik (biasa disebut bagian kepala, dan yang suka air) dan hidrofobik (yang disebut bagian ekor, yang tidak suka air). Surfaktan dapat digunakan sebagai bahan penggumpal, pembusaan, dan emusifier oleh industri farmasi, kosmetik, kimia, pertanian dan pangan serta industri produk perawatan diri (personal care product) [1].

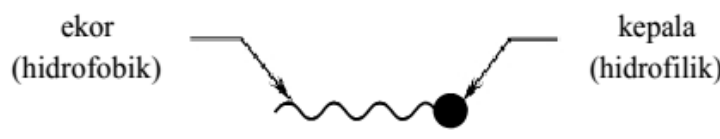

Gambar 1. Diagram Skematik dari Sebuah Molekul Surfaktan [2]

Molekul dari pada surfaktan memiliki struktur ampifilik yang memiliki kemampuan tarik menarik kepada air dan minyak. Bagian hidrofilik biasanya memiliki gugus $-\mathrm{COOH},-\mathrm{SO}_{3} \mathrm{H}$, dan rantai polioxi etilen, sementara bagian lipofilik memiliki gugus $\mathrm{Si}, \mathrm{CF}$, dan rantai polioxi propilen. Ketika hidrofilik memiliki gaya tarik yang lebih kuat dibanding lipofilik, ini menandakan surfaktan yang larut terhadap air dan demikian sebaliknya [3].

Stearamida merupakan salah satu asam lemak amida primer dengan rumus molekul $\mathrm{C}_{18} \mathrm{H}_{37} \mathrm{NO}$. Stearamida dapat dibuat dalam skala besar dan biasanya tersedia dalam bentuk butiran berbentuk tepung. Stearamida pada suhu kamar berwujud kristal yang jernih berwarna putih. Stearamida memiliki temperatur maksimum $220{ }^{\circ} \mathrm{C}$ [4]. Penggunaan asam stearat telah banyak digunakan pada sintesis surfaktan karena asam stearat dapat diperoleh dalam jumlah besar dari turunan minyak nabati seperti minyak kelapa sawit. Selain itu 
minyak nabati merupakan bahan yang paling sering ditemukan dan murah [5].

Hal yang perlu diperhatikan dalam proses ekstraksi adalah senyawa yang memiliki kepolaran yang sama akan lebih mudah tertarik dan terlarut dengan pelarut yang memiliki tingkat kepolaran yang sama. Penelitian ini menggunakan pelarut campuran antara isopropil alkohol dengan heksana. Penggunaan pelarut campuran ini dipilih karena berdasarkan kelarutan bahan baku dan produk terhadap pelarut dimana produk amida yang dihasilkan dan monoetanolamina ternyata lebih larut dalam pelarut alkohol yang bersifat polar sedangkan asam lemak murni kurang larut dalam pelarut polar tetapi lebih larut dalam pelarut non polar seperti heksana [6].

Pada penelitian ini, akan disintesis surfaktan stearamida dengan reaksi amidasi antara asam stearate dan urea. Katalis yang digunakan adalah katalis logam zirkonium (IV) klorida karena keberadaannya yang cukup melimpah dan kemampuan mereka yang dpat bekerja dengan baik dalam semua pelarut dan mudah untuk direcycle.

\section{Teori}

Surfaktan memiliki kegunaan yang sangat bervariasi, mulai dari bahan deterjen, farmasi, kosmetik, tekstil, makanan, plastik dan lainnya. Gugus hidrofilik pada surfaktan bersifat polar dan gugus lipofiliknya bersifat non polar. Surfaktan klasik diproduksi dari bahan baku petrokimia. Untuk ke depannya, bahan baku fosil akan berkurang dan produk dengan bahan baku yang terbarukan akan menjadi lebih penting [7]. Surfaktan alami adalah jenis surfaktan yang disintesis dari bahan alami. Sumbernya dapat berasal dari tanaman atau hewan dan produknya didapat melalui beberapa proses pemisahan, seperti: ekstraksi, presipitasi, atau distilasi. Surfaktan dimana salah satu struktur utamanya, bagian kepala ataupun ekor hidrofobik, didapat dari bahan alami biasanya disebut surfaktan alami [8].

Berdasarkan gugus hidrofiliknya, surfaktan digolongkan menjadi 4 yaitu [5] :

1. Surfaktan anionik

2. Surfaktan kationik

3. Surfaktan nonionik

4. Surfaktan amfoter

\section{Asam Stearat}

Asam stearat berbentuk kristal putih atau kekuningan, sedikit berbau, serta memiliki rasa seperti lemak. Metode pembuatan asam stearat meliputi hidrolisis lemak atau hidrogenasi asam lemak tak jenuh (misalnya asam oleat), kemudian dilanjutkan dengan metode isolasi, seperti distilasi fraksinasi ataupun kristalisasi. Konsentrasi asam stearat tertinggi diperoleh dari hidrogenasi asam lemak tak jenuh [11]. Asam stearat merupakan salah satu jenis asam lemak jenuh, yang mana asam lebih jenuh lebih stabil daripada asam lemak tidak jenuh [12].

Urea

Urea secara komersial diproduksi melalui dehidrasi ammonium karbamat $\left(\mathrm{NH}_{2} \mathrm{COONH}_{4}\right)$ pada tekanan dan suhu tinggi. Amonium karbamat diperoleh langsung melalui reaksi ammonia dengan karbon dioksida. Kedua reaksi tersebut biasanya dilakukan secara simultan pada reaktor bertekanan tinggi. Belakangan ini, urea digunakan secara komersial sebagai suplemen pakan ternak. Aplikasi penting lainnya adalah pada pembuatan resin, lem, pelarut, dan beberapa obat. Urea diklasifikan sebagai senyawa tidak beracun [13].

\section{Stearamida}

Stearamida merupakan salah satu asam lemak amida primer dengan rumus molekul $\mathrm{C}_{18} \mathrm{H}_{37} \mathrm{NO}$. Stearamida dapat dibuat dalam skala besar dan biasanya tersedia dalam bentuk butiran berbentuk tepung. Stearamida pada suhu kamar berwujud kristal yang jernih berwarna putih. Stearamida memiliki temperatur maksimum $220{ }^{\circ} \mathrm{C}$ dan stearamida banyak digunakan pada aplikasi seperti produksi karet.

Asam lemak amida, seperti stearamida, kebanyakan digunakan pada produksi kain anti air melalui reaksi dengan formaldehid, piridin, dan asam klorida untuk menghasilkan garam kuartener [9]. Stearamida dapat dihasilkan juga dengan reaksi antara asam stearat dan urea, berikut adalah reaksinya :

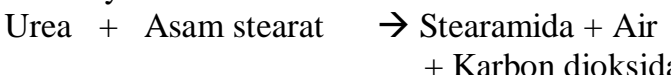

$\mathrm{CO}\left(\mathrm{NH}_{2}\right)_{2}+2 \mathrm{C}_{17} \mathrm{H}_{35} \mathrm{OOH} \rightarrow 2 \mathrm{C}_{17} \mathrm{H}_{37} \mathrm{NO}+\mathrm{H}_{2} \mathrm{O}$

$+\mathrm{CO}_{2}$

\section{Metode}

\section{Bahan dan Alat}

Alat yang digunakan dalam penelitian ini antara lain labu leher tiga, refluks kondensor, termometer, erlenmeyer, corong pisah, gelas ukur, gelas kimia, neraca analitik, pipet tetes, hot plate dan magnetic stirrer.

Bahan yang digunakan dalam penelitian ini adalah asam stearat, urea, zirkonium (IV) klorida $\left(\mathrm{ZrCl}_{4}\right)$. Pelarut : heksana dan 2-propanol. Bahan analisis : $\mathrm{KOH}$, phenolphthalein dan $\mathrm{HCl}$.

\section{Prosedur Reaksi Amidasi}

Asam stearat sebanyak $5 \mathrm{~g}$ dimasukkan ke dalam labu leher tiga. Ditambahkan pelarut heksana : 2propanol (1:1) dengan rasio pelarut : substrat (urea : asam stearat) (b/b) 6:1. Kemudian di masukkan katalis zirkonium (IV) klorida dengan kosentrasi 3\% terhadap berat asam stearat $(\% \mathrm{~b})$.

Dipanaskan dengan labu leher tiga dengan pemanas hot plate pada variasi suhu operasi $45^{\circ} \mathrm{C}$, 
$55^{\circ} \mathrm{C}, 65^{\circ} \mathrm{C}, 75^{\circ} \mathrm{C}, 85^{\circ} \mathrm{C}$ dan $95^{\circ} \mathrm{C}$. dan diaduk dengan kecepatan putar $250 \mathrm{rpm}$. Kemudian direaksikan dengan variasi waktu operasi 1 jam, 2 jam, 3 jam, 4 jam, 5 jam, 6 jam, 7 jam dan 8 jam. Setelah itu campuran disampling tiap 1 jam. Dihitung persen konversi.

\section{Hasil dan Pembahasan \\ Pengaruh Temperatur Reaksi Terhadap \% Konversi Asam Stearat}

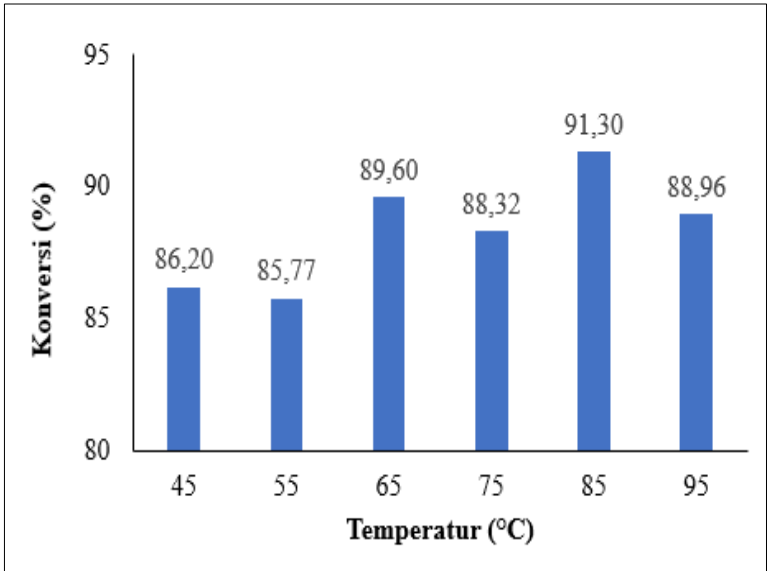

Gambar 2. Pengaruh Temperatur Reaksi Terhadap \% Konversi Asam Stearat

Pengamatan sintesis stearamida pada Gambar 2 menunjukkan pengaruh temperatur terhadap asam stearat. Diperoleh temperatur optimum pada suhu 85 ${ }^{\circ} \mathrm{C}$ memberikan konversi terbaik yaitu mencapai 91,30\%, dan mengalami fluktuasi pada temperatur 45, 55, 65, 75 dan $95^{\circ} \mathrm{C}$. Persen konversi terendah pada $55^{\circ} \mathrm{C}$ sebesar $85,77 \%$.

\section{Pengaruh Waktu Reaksi Terhadap \% Konversi Asam Stearat}

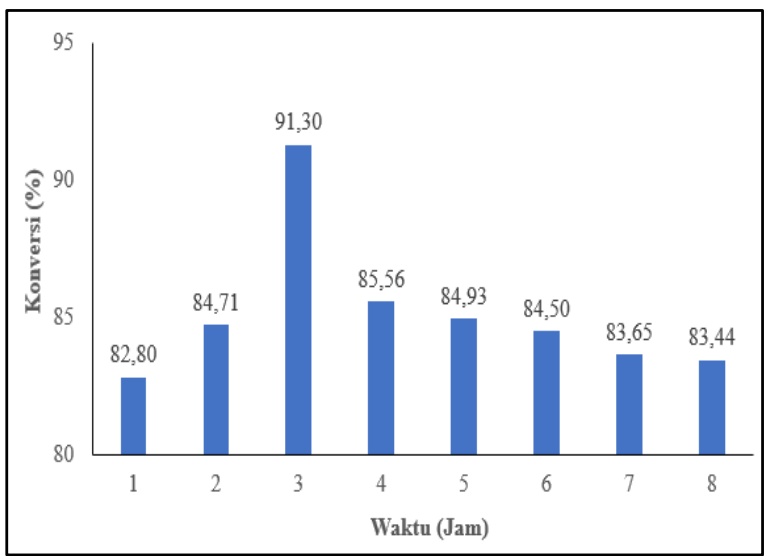

Gambar 3. Pengaruh Waktu Reaksi Terhadap \% Konversi Asam Stearat pada Temperatur Reaksi $85^{\circ} \mathrm{C}$

Pengamatan sintesis stearamida pada Gambar 3 menunjukkan pengaruh waktu reaksi terhadap asam stearat. Persen konversi terbesar yang diperoleh yaitu pada waktu reaksi 3 jam dengan persentase konersi sebesar 91,30\%. Persen konversi mengalami peningkatan dari waktu reaksi 1 jam menuju 3 jam. Namun, mengalami penurunan seiring bertambahnya waktu reaksi hingga 8 jam.

Hal ini disebabkan karena terjadinya reaksi samping seperti saponifikasi [14]. Sedangkan berdasarkan penelitian yang dilakukan oleh Wang, dkk. [13], peningkatan waktu reaksi tidak memberikan hasil yang signifikan terhadap perolehan amida [13]. Dari keterangan di atas dapat disimpulkan diperoleh waktu reaksi optimum selama 3 jam untuk sintesis stearamida.

\section{Kesimpulan}

Adapun kesimpulan penelitian ini adalah :

1. Kondisi reaksi terbaik pada penelitian ini untuk sintesis surfaktan stearamida yaitu waktu reaksi 3 jam dan temperatur reaksi $85^{\circ} \mathrm{C}$.

2. Kondisi reaksi terbaik pada penelitian ini memberikan konversi sebesar 91,30\%.

\section{Daftar Pustaka}

[1] A. S. Ma'as, Katalis, Bali : Universitas Udayana, 2011.

[2] Adisalamun, Pengembangan Proses Produksi Alkil Pologlikosida (APG) dari Glukosa dan Pati Sagu, Tesis, Fakultas Teknologi Agrikultur, Institut Pertanian Bogor, 2012.

[3] E. A. J. Al-Mulla, W. M. Z. W. Yunus, N. A. B. Ibrahim, And M. Z. A. Rahman, Difatty Acyl Urea from Corn Oil : Synthesis and Characterization. Department Chemistry, Faculty of Science, University Putra Malaysia, 2010.

[4] J. M. Pestman, Carbohydrate-Derived Surfactants Containing an N-Acylated Amine Functionality : Fundamental Aspects and Practical Applications, Disertasi Rijksuniversiteit Groningen, 1998.

[5] J. R. Oppusungu, V. R. Siregar dan Z. Masyithah, Pengaruh Jenis Pelarut Dan Temperatur Reaksi pada Sintesis Surfaktan Dari Asam Oleat Dan N-Metil Glukamina Dengan Katalis Kimia, Jurnal Teknik Kimia USU, Vol. 4, No. 1 (2015).

[6] K. Holmberg, Natural Surfactants, Current Opinion in Colloid \& Interfase Science, 2001, $6: 148-159$.

[7] M. A. Liebert, Final Report on the Safety Assessment of Oleic Acid, Lauric Acid, Palmitic Acid, Myristic Acid, and Stearic Acid, M. A. Liebert Publishers, USA, 1987.

[8] N. P. Awasthi and R P Singh, Lipase-catalyzed Synthesis of Fatty Acid Amide (Erucamide) Using Fatty and Urea, Department of Oil, 2007.

[9] R. E. Kirk and D. Othmer, Kirk-Othmer Encyclopedia of Chemical Technology, John Wiley \& Sons : New York, 2014. 
[10] R. J. Fessenden dan J. S. Fessenden, Kimia Organik, Edisi Ketiga, Jilid 2, Erlangga : Jakarta, 1986.

[11] S. Aisyah, Produksi Surfaktan Alkil Poliglikosida (APG) dan Aplikasinya pada Sabun Cuci Tangan Cair, Tesis, Fakultas Teknologi Agrikultur, Institut Pertanian Bogor, 2011.

[12] T. Zhu, C. L. Yuan, Z. Z. Xu, M. X. Fan, H. Y. Liu, and Y. H Xie, Study On Characteristics and Harm Of Surfactants, Journal of Chemical and Pharmaceutical Research, 2014, 6 (7): 2233-2237.

[13] X. Wang, Scalable Synthesis Of Oleoyl Ethanolamide by Chemical Amidation In A Mixed Solvent, J Am Oil Chem Soc, 2016, 93 : 125-131.

[14] Z. Masyithah, Optimasi Sintesis Surfaktan Alkanolamida dari Asam Laurat dengan Dietanolamina dan N-Metil Glukamina Secara Enzimatik, Disertasi, Universitas Sumatera Utara, 2010. 